\title{
Effect of Breed and Egg Weight on the Weight of Day-Old Chick in Kuroiler and Chabro Breeds of Poultry
}

\author{
Poonam Yadav ${ }^{1 *}$, Mahesh Datt ${ }^{1}$, Athar Uddin ${ }^{1}$, L.R. Yadav², \\ Brijesh Yadav ${ }^{3}$ and Suresh Yadav ${ }^{4}$ \\ ${ }^{1}$ Department of Livestock Production Management, SKNAU, Jobner-303329, India \\ ${ }^{2}$ Department of Agronomy, SKNAU, Jobner-303329, India \\ ${ }^{3}$ Division of Agricultural Physics, IARI, New Delhi-110012, India \\ ${ }^{4}$ Division of Genetics, IARI, New Delhi-110012, India
}

*Corresponding author

Keywords

Breed, Egg weight, Chick

Article Info

Accepted:

07 July 2019

Available Online:

10 August 2019

\section{A B S T R A C T}

An investigation was carried out to study the effect of strain and egg weight on chick's weight in large, medium and small sized eggs of chicken strains. The study was conducted at poultry farm, SKN College of Agriculture, Jobner. A total of 297 eggs were collected and grouped into three egg size categories i.e. Small (38-44 g), medium (45-52 g) and large (53-59 g). For Kuroiler breed of chicken, the chick weight was found significantly higher in medium class $(38.5 \mathrm{~g})$ followed by small $(34.3 \mathrm{~g})$ and large $(38.1 \mathrm{~g}) \mathrm{egg}$ classes. In the case of Chabro breed, it was significantly higher in medium (40.6 g) egg class followed by small (36.85 g) and large (40.3 g) egg classes. Chabro breed was better performer than Kuroiler breed for all three egg weight classes of eggs. The average weight of day old chick was increased in Chabro breed by $1.7 \%, 2.03 \%$ and $2.15 \%$ for small, medium and large classes, respectively over Kuroiler breed.

\section{Introduction}

Poultry is fastest growing sector of Indian agriculture today. Production of good-quality chicks is the prime objective of modern hatcheries in the world. One of the main genetic factor that affect the subsequent productivity of layer and broiler chicken is egg weight. Effect of egg size on post hatch performance of broiler chicks has an important economic impact. Though lot of work has been carried out on egg quality traits of established breeds, the information on varieties developed and being popularized for backyard farming in rural and tribal areas are limited.

The detailed characterization of these breeds with respect to its egg production, hatchability and growth performance traits are generally 
unavailable. Though precise information is not available, yet it is certain that backyard poultry is significantly contributing to the nutritional and livelihood security amongst rural poor. The modern broiler chicken has been reported to be able to achieve the same body weight in less than a third of the time as compared to their random bred predecessors (Havenstein et al., 2003). This places greater emphasis on the egg under which this embryonic period of growth occurs. As a result, knowing the effect of egg weight on chick hatch weight has become very important. Dudusola (2013) also reported that parental age and egg weight had a very significant effect on the chick weight. This increase in chick size due to increasing egg weight which is attributable to the fact that egg weight, yolk weight and albumen weight increases as the age increases in chickens while egg shell quality deteriorates as reported by (Hurnik et al., 1997). A close correlation between egg weight and hatching weight in domestic birds has also been documented (Abiola, 1999). A high correlation was found between egg weight and final chick weight, the economic importance of egg weight is worthy of note (Wilson, 1991).

Hence, precise knowledge of weight of dayold chick in correlation with egg weight of a particular variety of birds can be helpful in logical selection of fertile eggs. Therefore, the present study was designed to determine the effect of egg weight on chicks' weight in large, medium and small sized eggs of broiler chicken.

\section{Materials and Methods}

The experiment was carried out on two strains of back yard poultry viz. Kuroiler and Chabroat Poultry Farm, S.K.N. College of Agriculture, Jobner, District Jaipur, (Rajasthan). A total of 297 eggs were collected for this study. The eggs were weighed individually using weighing balance and grouped into three egg size categories as follows: Small (38-44 g), medium (45-52 g) and large (53-59 g). Each treatment had 198 eggs with 99 eggs per replicate. All eggs were incubated in incubator at $99.50^{\circ} \mathrm{F}-99.75^{\circ} \mathrm{F}$ $\left(37.5^{\circ} \mathrm{C}\right)$ with $60-65 \%$ relative humidity.

After hatching, subsequent weight of chick was recorded. Data were analyzed using Completely Randomized Design (CRD) $(\mathrm{P}<0.01)$.

\section{Results and Discussion}

Table 1 shows the average weight of day old chick for both breeds. For Kuroiler breed of chicken, the chick weight was found significantly higher in medium class $(38.5 \mathrm{~g})$ followed by small (34.3g) and large (38.1 g) egg classes. Similar trend was observed for Chabro breed and it was found significantly highest in medium (40.6 g) egg class followed by small (36.85 g) and large (40.3 g) egg classes (Fig. 1). Between the two breeds, Chabro breed of chicken has higher chick weight as compared to Kuroiler breed of chicken for all three egg weight classes. The average weight of day old chick was found increased in Chabro breed by $1.7 \%, 2.03 \%$ and $2.15 \%$ for small, medium and large classes respectively over Kuroiler breed of chicken (Fig. 2).

Results were in agreement with the result obtained by Dudusola (2013) who reported that egg weight had a significant effect on the chick weight and weight of the day-old chick increases significantly higher for medium class than small class or large class. This increase in chick size may be due to increasing egg weight is attributable to the fact that egg weight, yolk weight and albumen weight increase as the age increases in chickens while egg shell quality deteriorates as reported by (Hurnik et al., 1997). 
Table.1 Effect of egg weight (g) on the weight of day old chick of Kuroiler and Chabro breeds

\begin{tabular}{|l|c|c|}
\hline Parameters & Kuroiler & Chabro \\
\hline Small & 34.3 & 36 \\
\hline Medium & 38.5 & 40.6 \\
\hline Large & 38.1 & 40.3 \\
\hline SE(m) & 0.06 & 0.1 \\
\hline CD & 0.14 & 0.24 \\
\hline CV & 0.31 & 0.53 \\
\hline S/NS & $\mathrm{S}$ & $\mathrm{S}$ \\
\hline
\end{tabular}

S-Significance $(\mathrm{p}<0.01)$

Figure in parenthesis is arcsine values

Fig.1 Weight of day old chick for different egg classes of Chabro and Kuroiler breeds

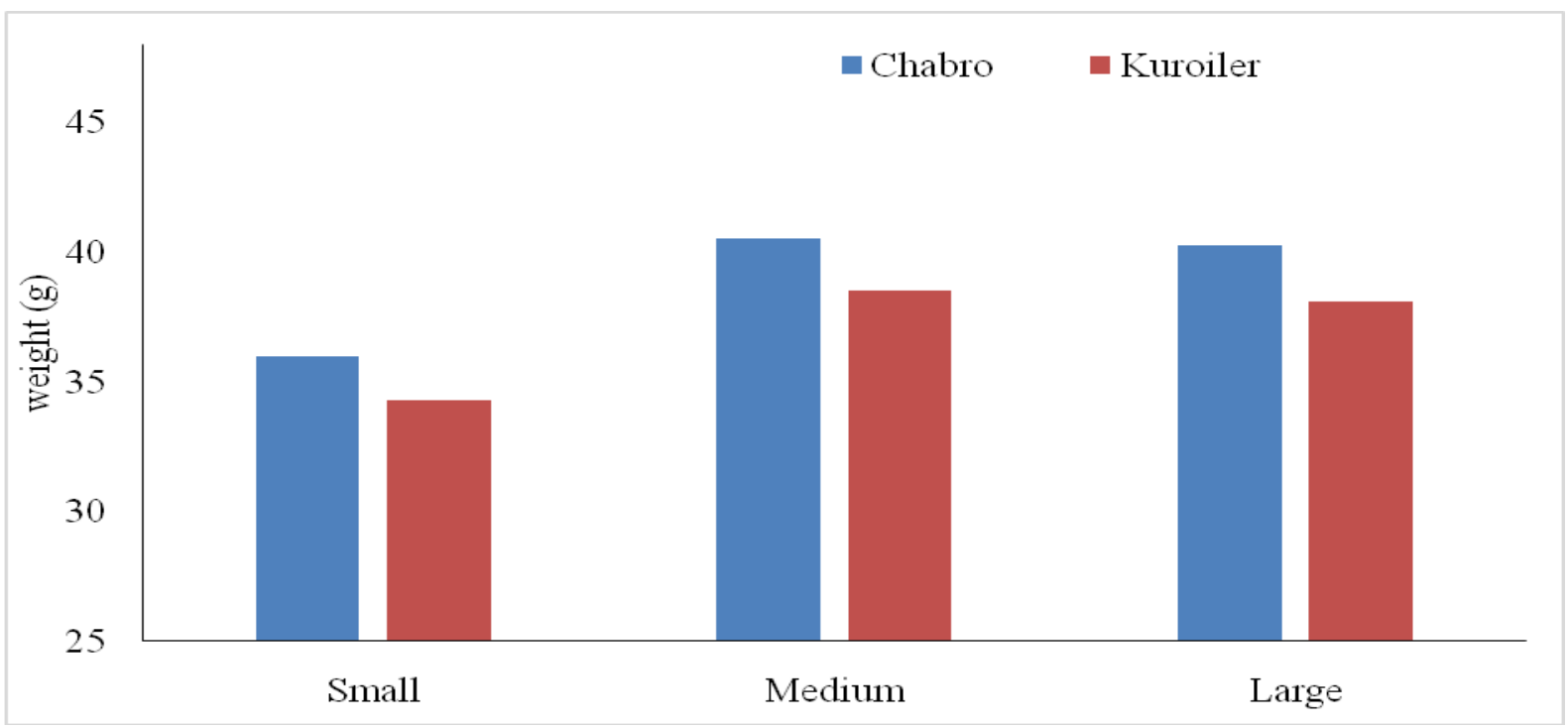

Fig.2 Percent changes in weight of day old chick of Chabro breed over Kuroiler breed

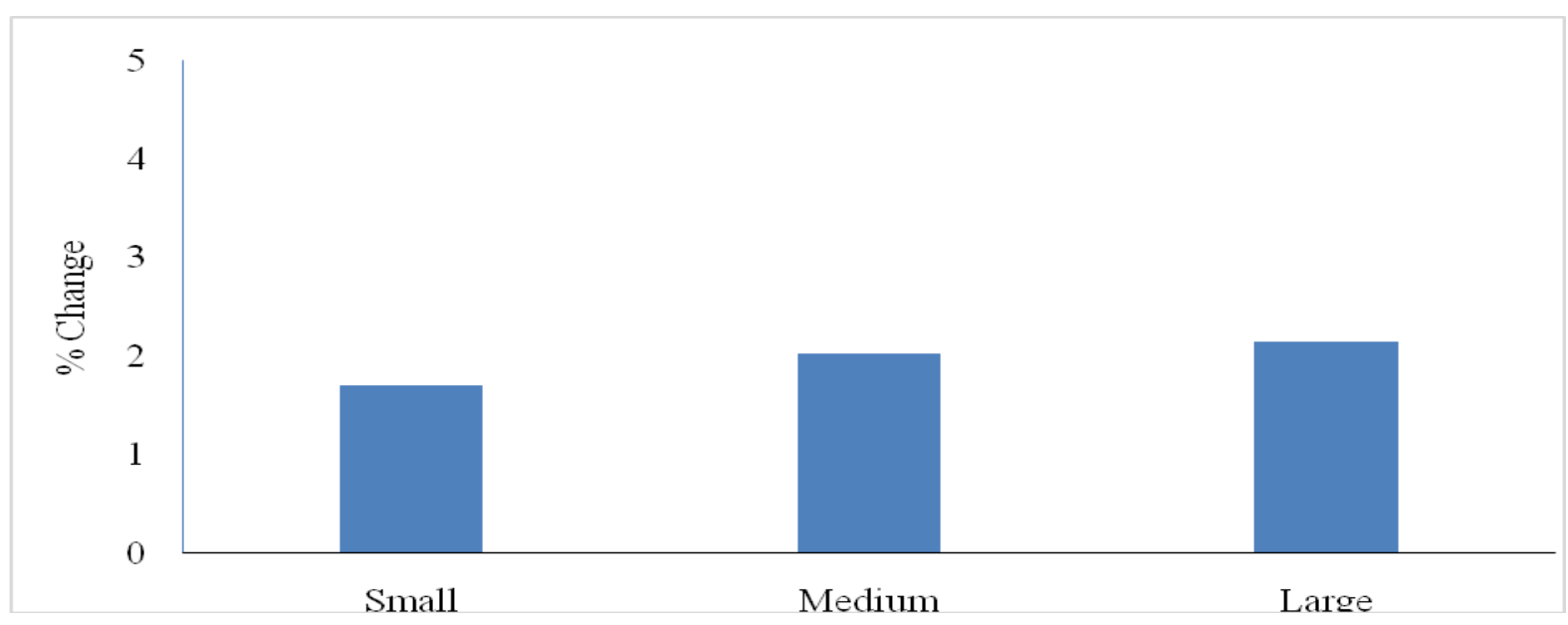


An experiment was conducted to study the effect of strain and egg weight on chick's weight in large, medium and small sized eggs of chicken strains. The study was conducted at poultry farm of SKN College of Agriculture, Jobner. A total of 297 eggs were collected for this study. These eggs were grouped into three egg size categories i.e. Small (38-44 g), medium (45-52 g) and large (53-59 g).For Kuroiler breed of chicken, the chick weight was found significantly higher in medium class (38.5 g) followed by small (34.3 g) and large (38.1g) egg classes. In the case of Chabro breed, it was significantly higher in medium (40.6 g) egg class followed by small (36.85 g) and large (40.3 g) egg classes. Chabro breed was better performer than Kuroiler breed for all three egg weight classes of eggs.

\section{References}

Abiola, S.S. 1999. Effects of turning frequency of hen's egg in electric table- type incubator on weight losses, hatchability and mortality. Nigeria. Agriculture journal. 30:77-82

Dudusola, I. O. 2013. The effect of parental age and egg weight on fertility, hatchability and day-old chick weight of Japanese quail (Cortunix cortunix japonica). Standard Research Journal of Agricultural Sciences. 1(2), 13-16.

Havenstein, G.B. Ferket, P.R. and Qureshi, M.A., 2003. Growth, liveability, and feed conversion of 1957 versus 2001 broilers when fed representative 1957 and 2001 broiler diets. Poultry Science. 82: $1500-1508$.

Hurnik J. F., Summer J. D., Reinhard B. S., Sweirczewks A. 1997. Effects of age in the performance of laying hens during the first year of production. Poult. Sci. 56: 222-230

Wilson, H.R. 1991. Interrelationships of egg size, chick size, post hatching growth and hatchability. World's Poult. Sci. J. 47: 5- 20 .

\section{How to cite this article:}

Poonam Yadav, Mahesh Datt, Athar Uddin, L.R. Yadav, Brijesh Yadav and Suresh Yadav. 2019. Effect of Breed and Egg Weight on the Weight of Day-Old Chick in Kuroiler and Chabro Breeds of Poultry. Int.J.Curr.Microbiol.App.Sci. 8(08): 519-522.

doi: https://doi.org/10.20546/ijcmas.2019.808.060 